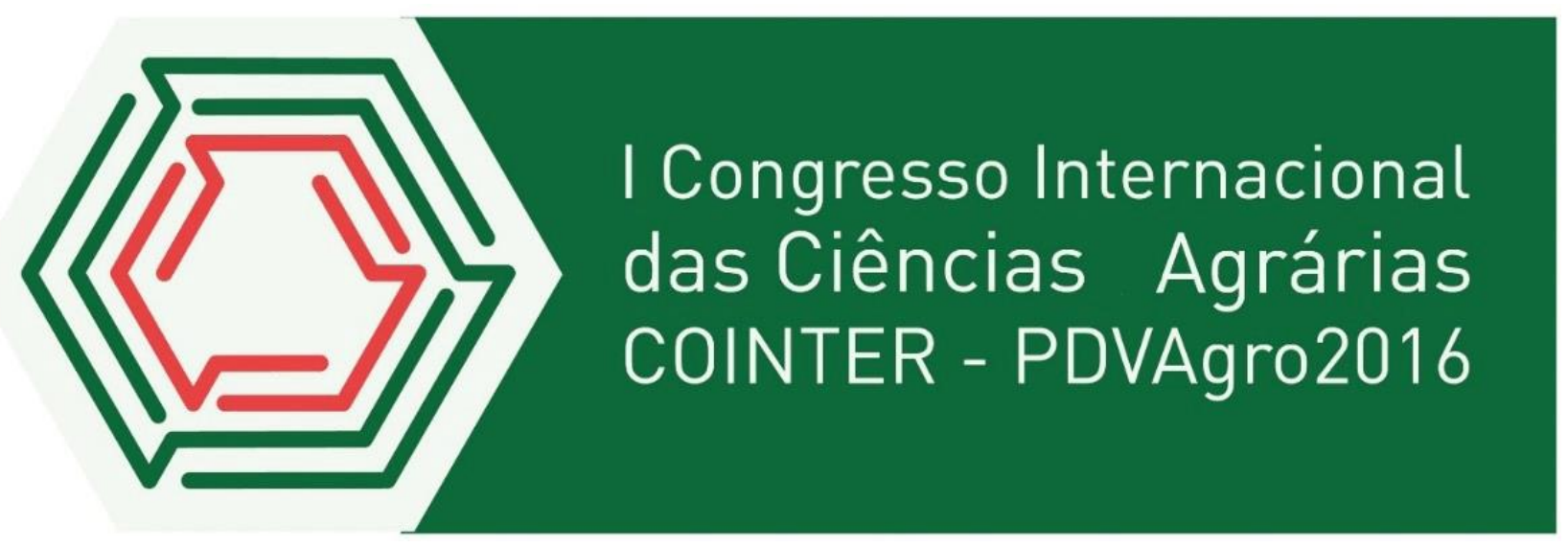

\title{
CARACTERÍSTICAS AGRONÔMICAS DA BETERRABA (BETA VULGARIS L.) EM FUNÇÃO DA IRRIGAÇÃO COM ÁGUA SALINA E BIOFERTILIZANTE
}

\begin{abstract}
Ednardo Gabriel de Sousa ${ }^{1}$; Leandra de Melo Calvante Sousa ${ }^{2}$; Antônio dos Santos Silva ${ }^{3}$; Daivyd Silva de Oliveira ${ }^{4}$; Thiago Jardelino Dias ${ }^{5}$.
\end{abstract}

\section{Introdução}

Pertencente á família Quenopodiácea, a beterraba (Beta vulgaris L.) é cultivada comercialmente em diversas regiões do Brasil, incluindo a região Nordeste (Grangeiro et al., 2011).

O Nordeste brasileiro apresenta má distribuição de água doce, restando como opção a utilização de águas de qualidade inferior para irrigação (MENDES, 2008). Diante disso, Ayers \& Westcot (1991) e Deuner et al. (2011), afirmaram que a beterraba tolera salinidade limiar de 7,0 dS $\mathrm{m}^{-1}$.

Em regiões áridas e semiáridas, a salinidade é fator limitante na produção agrícola (José, 2014). Nessa perspectiva verifica-se que a utilização das substâncias húmicas na tentativa de amenizar os efeitos da salinidade sob as cultivares torna-se uma alternativa.

\section{Fundamentação Teórica}

\footnotetext{
${ }^{1}$ Mestrando em Ciências Agrárias (Agroecologia), Universidade Federal da Paraíba, ednardogabriel@ hotmail.com;

${ }^{2}$ Mestrando em Agronomia, Universidade Federal da Paraíba, leandramelo2502@ hotmail.com;

${ }^{3}$ Graduado em Ciências Agrárias, Universidade Federal da Paraíba, antoniocchsa@ hotmail.com;

${ }^{4}$ Mestrando em Agronomia, Universidade Federal da Paraíba, daivydoliver@ hotmail.com;

${ }^{5}$ Doutor, Universidade Federal da Paraíba, thiagojardelinodias@ gmail.com .
} 
A elevada demanda por alimento favoreceu a expansão das áreas agrícolas, e consequentemente observa-se o crescimento da produção de hortaliças em regiões áridas e distante dos grandes centros (Gheyi et al., 2012).

Assim sendo, a beterraba (Beta vulgaris L.), torna-se opção de cultivo destinada ao semiárido, uma vez que suporta condições de solos salinos (Katerji et al., 1997), e detém diversidade de componentes nutricionais (Aquino et al., 2006).

Todavia, Souza (2008) sugere a aplicação de biofertilizante, como inibidor do acúmulo de sais no solo decorrente da irrigação.

\section{Metodologia}

O presente ensaio científico trata-se de uma pesquisa quantitativa, desenvolvida no período de outubro de 2014 a fevereiro de 2015, em estufa, localizada no campo experimental do CCHSA/UFPB, em Bananeiras - PB. O delineamento experimental foi distribuído em bloco casualizados, com 6 repetições, em esquema fatorial $6 \times 3$, referentes as seis condutividades elétrica de água de irrigação: 0,$5 ; 1,5 ; 2,5 ; 3,5 ; 4,5 ; 5,5 \mathrm{dS} \mathrm{m}^{-1}$, via solo com biofertilizante comum aos níveis de $0 \% ; 10 \% ; 20 \%$ da lâmina de irrigação aplicados, quinzenalmente, perfazendo 108 unidades experimentais.

\section{Resultados e Discussões}

Observa-se que a salinidade exerceu efeito negativo no número de folha (Figura 1). Resultados semelhantes também foram encontrado por Cavalcante et al. (2011), onde constatou-se efeito depreciador da irrigação com água salina no cultivo de tomate.

Figura 1. Número de folhas de beterraba em função de diferentes condutividades de água

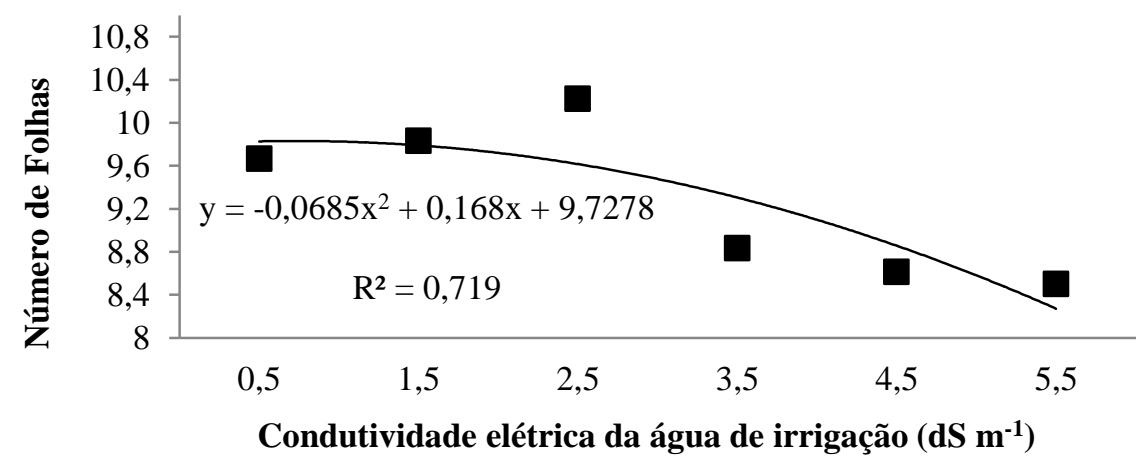


Os níveis crescentes de condutividades da água (Figura 2), exerceram efeito atenuante no índice de clorofila $a$, apresentando $47,62 \mu \mathrm{g} \mathrm{cm}$. Sabendo disso, pode-se definir que a taxa fotossintética foi influenciada pelas concentrações das salinidades avaliadas (Centritto et al., 2003).

Figura 2. Clorofila $a$ da beterraba submetida a diferentes condutividades de água

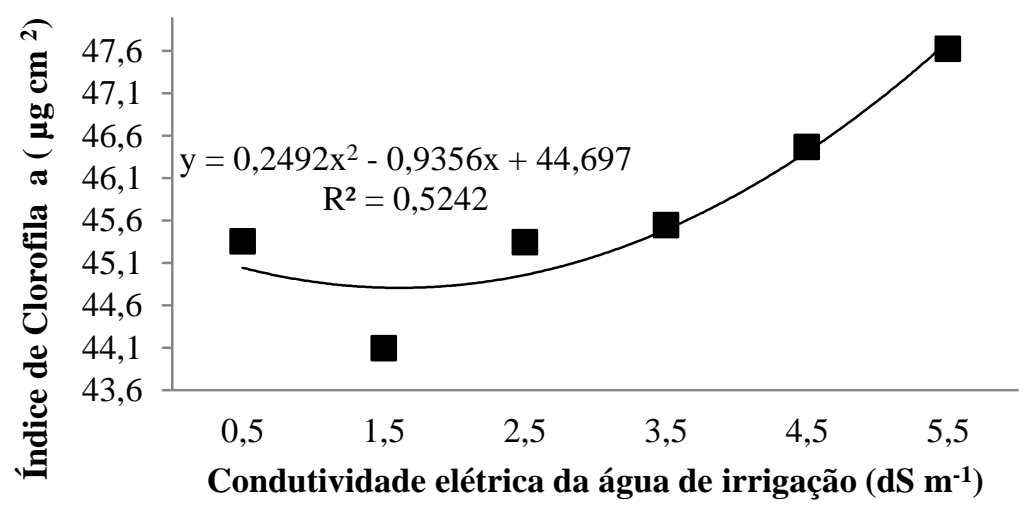

O efeito quadrático para índice de clorofila b (Figura 3) demonstra que a elevação do nível de salinidade exerce interação significativa. Resultados semelhante foram observados por Cavalcante et al. (2011), quando trabalhando com clorofila e carotenoides em maracujazeiro-amarelo irrigado com água salina no solo com biofertilizante bovino, obtiveram comportamento similares, isso implica dize que alta salinidade inibiu a produção do índice de clorofila b.

Figura 3. Índice de clorofila $b$ da beterraba

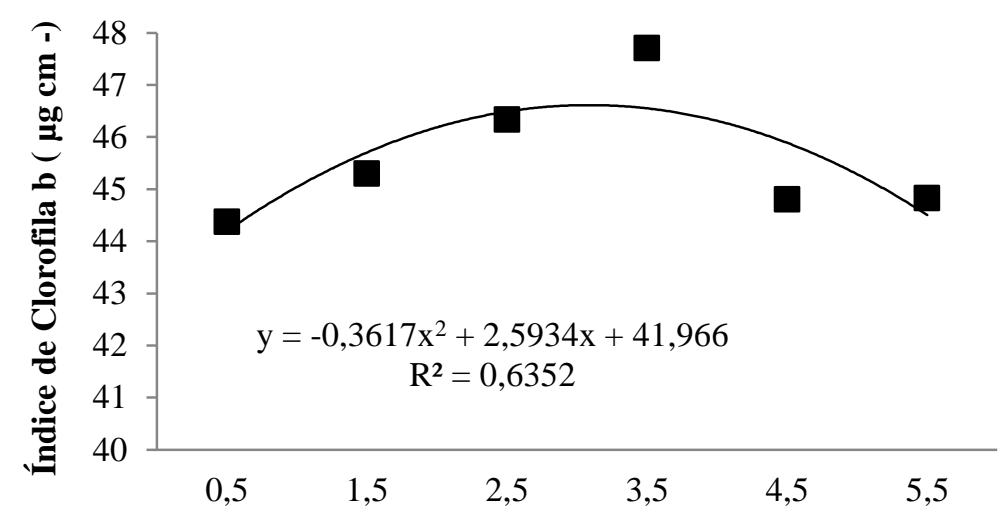

Condutividade elétrica da água de irrigação $\left(\mathrm{dS} \mathrm{m}^{-1}\right)$

Verificou-se efeito quadrático para a clorofila total (Figura 4), isso se deve aos níveis elevados de condutividade da água, comprometendo significativamente o desenvolvimento do índice de clorofila total, até atingir a condutividade $4,5 \mathrm{dS} \mathrm{m}^{-1}$. Entretanto a condutividade de água de 5,5 dS m $\mathrm{m}^{-1}$, afetou o índice de clorofila total promovendo declínio. Todavia, Cavalcante et al. 
(2009) afirma que o crescimento vegetal, sob condições de salinidade têm sua atividade fotossintética reduzida, resultando na menor redução do crescimento com menor área foliar e menor conteúdo de clorofila.

Figura 4. Índice de clorofila total da Beterraba

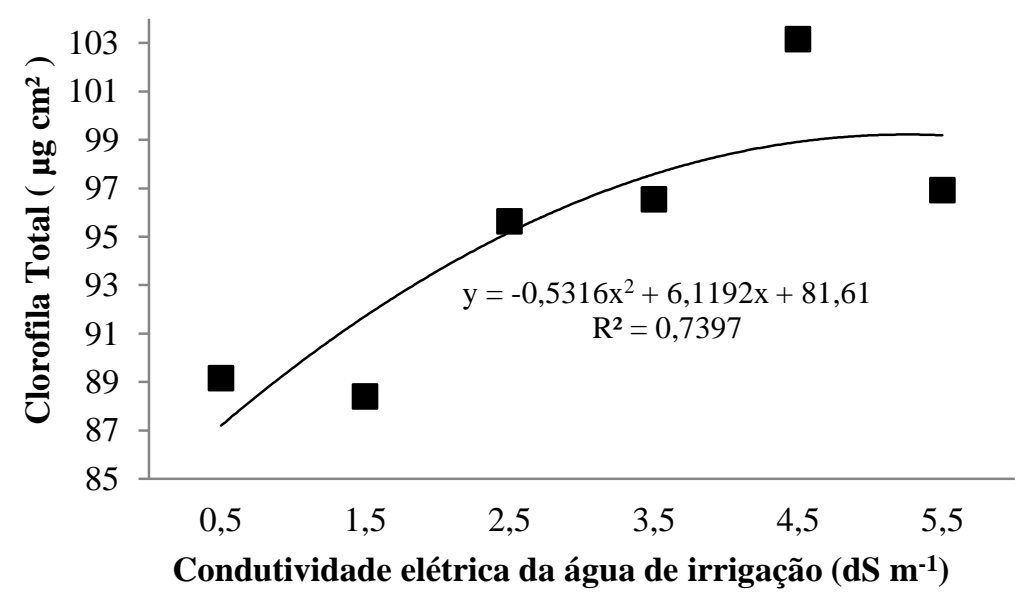

\section{Conclusões}

1. O uso do biofertilizante não surtiu efeito significativo no controle da condutividade elétrica da água de irrigação sob a cultura;

2. O aumento da condutividade elétrica da água de irrigação resultou em perdas do rendimento do número de folhas, causando um desequilíbrio fisiológico afetando negativamente o desenvolvimento da planta.

\section{Referências}

AQUINO, L. A.; PUIATTI, M.; PEREIRA, P. R. G.; PEREIRA, F. H. F.; LADEIRA, I. R.; CASTRO, M. R. S. Produtividade, Qualidade e Estado Nutricional da Beterraba de Mesa em Função de Doses de Nitrogênio. Horticultura Brasileira, v.24, p.199- 203, 2006.

AYERS, R.S.; WESTCOT, D.N. FAO: Organização das Nações Unidas para a Agricultura e alimentação. A qualidade da água na agricultura. Campina Grande - PB: UFPB, 1999. 218p. (Estudos FAO irrigação e drenagem, n.29, revisado). 
DEUNER, C.; MAIA, M.S.; DEUNER, S.; ALMEIDA, A.S.; MENEGHELLO, G.E. Viabilidade e atividade antioxidante de sementes de genótipos de feijão-miúdo submetidos ao estresse salino. Revista Brasileira de Sementes, v. 33, n.4, p.711 - 720, 2011.

CAVALCANTE, L.F.; VIEIRA, M.S.; SANTOS, AILTON FRANCISCO . Água salina e esterco bovino líquido na formação de mudas de goiabeira cultivar paluma. Revista Brasileira de Fruticultura, p.251-261, 17 out. 2009.

CAVALCANTE, L.F.; DIAS, T.J.; NASCIMENTO. R.; FREIRE, J.L.O.; Clorofila e carotenoides em maracujazeiro-amarelo irrigado com águas salinas no solo com biofertilizante bovino. Revista Brasileira de Fruticultura, São Paulo, p.699-705, out. 2011.

FILHO, D. H. G.; SANTOS, J. B.; GHEYI, H. R.; CAVALCANTE, L.F. \& JUNIOR, J. A. S.. COMPONENTES DE PRODUÇÃO E RENDIMENTO DO GIRASSOL SOB IRRIGAÇÃO COM ÁGUAS SALINAS E ADUBAÇÃO NITROGENADA. Irriga, Botucatu, v. 20, n. 3, p. 514-527, julho - setembro, 2015 ISSN ONLINE 1808-8546/ISSN CD 1808-3765.

GHEYI, H. R.; MEDEIROS, S.S.; GALVÃO, C. O. (Ed.). RECURSOS HídRICOS EM REGIÕES SEMIÁRIDAS: ESTUDOS E APLICAÇÕES. Campina Grande: INSA, 2012. $258 \mathrm{p.}$

GRANGEIRO, L.C.; SANTOS, A.P.; FREITAS, F.C.L.; SIMÃO, L.M.C.; BEZERRA NETO, F. Avaliação agroeconômica das culturas da beterraba e coentro em função da épocaa de estabelecimento do consórcio. Revista Ciência Agronômica, v.42, n.1, p.242-248, 2011.

MENDES, A. M. S.; SANTOS, E. E. F.; SILVAM, D. J.; MARTINEZ, E. A.; DOURADO, D. L.; OLIVEIRA, J. M.; SANTOS, N. T. dos. Crescimento e acúmulo de nutrientes em plantas de Sorgum bicolor $\mathbf{L}$ Moench sob irrigação com águas de diferentes concentrações salinas. In: Reunião Brasileira de Manejo e Conservação do Solo e da Água, 17. 2008, Rio de Janeiro. Rio de Janeiro: SBCS: Embrapa Solos: Embrapa Agrobiologia, 2008. Embrapa Solos. Documentos, 101. 
JOSÉ L. DE A. S; JOSÉ, F.M.; SAMARA, S. V.; ALVES, F.A. O; MANOEL J.S. JUNIOR \& IARAJANE B. N. Uso de águas salinas como alternativa na irrigação e produção de forragem no semiárido nordestino. Revista Brasileira de Engenharia Agrícola e Ambiental- UAEA/UFCG http://www.agriambi.com.br Protocolo S11.14 - 05/02/2014 • Aprovado em 28/03/2014 ISSN 1807-1929 v.18, (Suplemento), p.S66-S72, Campina Grande, PB, 2014.

KATERJI, N.; HOOM, J. W.; HAMDY, A.; MASTRORILLI, M.; KARZEL, E. M. Osmotic Adjustment of Sugar Beets in Response to Soil Salinity and its Influence on Stomatal Conductance, Growth and Yield. Agricultural Water Management, v.34, p.57-69, 1997.

SOUSA, G. B.; CAVALCANTE, L.F; CAVALCANTE, Í.H.L.; BECKMANN-CAVALCANTE, M. Z. ; NASCIMENTO, J. A. Salinidade do Substrato Contendo Biofertilizante para formacão de Mudas de Maracujazeiro Irrigado com Àgua Salina. Caatinga (Mossoró,Brasil), v.21, n2, p.172-180 maio/junho de 2008. 